\title{
Decreased axial bone mineral density in perimenopausal women with rheumatoid arthritis-a population based study
}

\author{
Heikki Kröger, Risto Honkanen, Seppo Saarikoski, Esko Alhava
}

\begin{abstract}
Objectives-Although periarticular osteoporosis is a well-recognised phenomenon in rheumatoid arthritis (RA), there is considerable controversy over whether RA is associated with more generalised osteoporosis. The aetiology of this bone loss is probably multifactorial, including both life-style risk factors and diseaserelated determinants. Population-based studies on bone mineral density (BMD) in RA have not previously been conducted, and the purpose of the present crosssectional population-based study was to determine whether patients with $R A$ are at an increased risk of having osteoporosis. Furthermore, the determinants of BMD in RA patients were investigated.

Methods-BMD at the spine and femoral neck was measured in 143 women with RA. The control group consisted of 1611 women with no disease or taking any drugs known to affect bone metabolism. The study population was a random stratified sample from the Kuopio Osteoporosis Study, which included all perimenopausal women aged 47-56 years residing in Kuopio Province, Eastern Finland in $1989(n=14220)$. The mean age of the patients at the time of densitometry was $53 \cdot 7$ years.
\end{abstract}

Results-The mean (SD) spinal and femoral neck BMD was significantly lower in patients with RA compared with controls [spine: $1.067 \quad(0.161) \quad v \quad 1.129$ $(0.157) \mathrm{g} / \mathrm{cm}^{2}, \mathbf{p}<0.001$; femoral neck:

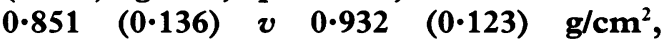
$\mathbf{p}<0.001]$. Analysis of variance showed that at the spine the difference was significant only in patients having corticosteroid treatment, whereas at the femoral neck patients with non-steroid treatment also had significantly lower BMD. When confounding factors were corrected, no significant difference could be found between non-steroid and corticosteroid treated patients with $R A$, suggesting that the independent effect of corticosteroids on BMD is only minimal. Multiple regression analysis found age, weight and functional grade to be significant predictors of spinal BMD $\left(R^{2}=0 \cdot 403, p<0 \cdot 001\right)$. In the femoral neck weight, cumulative corticosteroid dose and functional grade were significant predictors of $B M D\left(R^{2}=0 \cdot 410, p<0 \cdot 001\right)$.
Conclusions-RA is associated with generalised osteoporosis. The physical impairment and body weight are the major determinants of both spinal and femoral bone mass in RA patients. The cumulative corticosteroid dose was also a significant determinant of femoral neck BMD. However, the independent effect of corticosteroids is questionable because the use of corticosteroids may be an indicator of more severe disease.

(Ann Rheum Dis 1994; 53: 18-23)

Periarticular osteoporosis is a well recognised phenomenon of rheumatoid arthritis (RA). There is, however, considerable controversy over whether RA is also associated with generalised axial osteoporosis. ${ }^{1-4}$ Many potential factors, both life-style and disease related, may contribute to axial bone mass and bone loss, and this may explain the varying results in previous studies. Disease activity and reduced mobility are frequently suggested as being responsible for this bone loss. Besides the disease itself, the treatment may also cause increased bone loss. There is no doubt that high doses of corticosteroids are deleterious for bone. However, whether low dose corticosteroids result in an increased risk of osteoporosis is a matter of debate..$^{5-7}$ Differences in daily dose of corticosteroids, duration of the treatment and activity of RA, could explain the discrepant findings. Furthermore, cortical and trabecular bone may behave in a different way under corticosteroid treatment.

To our knowledge, no population based study using axial bone densitometry has been conducted on RA. In the present study a random stratified sample of perimenopausal women with RA was studied using dual-energy $x$-ray absorptiometry (DXA) of the spine and femoral neck. The bone mineral density data of patients with RA were compared with the data for a healthy female population of the same age, and possible predictors of BMD in RA were investigated.

\section{Subjects and Methods}

STUDY POPULATION

The initial study population consisted of 14220 women aged 47-56 years residing in Kuopio Province, Eastern Finland, in February 1989. The baseline postal enquiry 
was sent to 14121 in 1989 , and 13100 $(92 \cdot 8 \%)$ responded. ${ }^{8}$ The enquiry included questions about gynaecological history and surgery, use of female hormones, parity, height, weight, physical activity at work and during leisure, consumption of milk, smoking, morbidity and current use of prescribed drugs. The length of time that subjects had been smoking regularly and the number of cigarettes consumed currently per day were registered. Another postal enquiry was sent during 1990-91 to those women who were selected for bone densitometry (see below). It included questions about the use of coffee and alcohol. In addition, it specified the amount of physical activity. Both questionnaires were checked through with each participant at the time of bone densitometry.

An estimate of dietary calcium intake was derived from the consumption of milk products $(1 \mathrm{dl} \mathrm{milk}=120 \mathrm{mg}$ calcium, 1 slice cheese $=87 \mathrm{mg}$ calcium). Weekly hours of regular physical exercise, daily walking or running distance, and the physical demands of work (sitting, light, medium, heavy) were combined into a 3 category overall physical activity level (I-III).

The grip strength of the dominant arm was assessed with a hand-held dynamometer (Martin Vigorimeter, Germany), with a mean of 3 measurements being recorded per subject.

A total of $11055(84 \cdot 4 \%)$ respondents were willing to have bone densitometry. BMD was measured from a random stratified sample of 3222 women $(29 \cdot 1 \%)$ during $1990-91$ at Kuopio University Hospital by trained personnel. The study was approved by the ethical committee of Kuopio University Hospital.

\section{PATIENTS WITH RA}

Four hundred and seventy four $(3.6 \%)$ of the women who returned the postal enquiry reported suffering from RA. A third questionnaire was sent out to those RA patients who were or had been treated with oral corticosteroids $(n=56)$ and to a $32 \%$ random sample of other patients reported to have RA ( $n=133)$. The questionnaire included questions about disease duration, medication history, operations, and daily functional ability, and the diagnosis of RA was confirmed with the help of this questionnaire. On the basis of the questionnaire all 56 women with corticosteroid treatment and $65 \%(n=87)$ of other women were considered to have definite RA. Thus the final study group consisted of 143 women. To test the validity of the RA diagnosis, we checked the medical records of all women, residing in the city of Kuopio $(n=45)$. Forty one $(91 \cdot 1 \%)$ had definite RA.

The mean (SD) age of the patients at the time of BMD measurement was $53.7(2.9)$ years (range 48-59 years). One hundred and six women were postmenopausal. The RA patients were divided into four functional grades (FG) according to their functional ability and overall physical activity:

1 Moderately or severely reduced functional ability.
2 Slightly reduced functional ability + decreased physical activity.

3 Normal functional ability + normal physical activity.

4 Normal functional ability + increased physical activity.

Characteristics of RA patients and controls are presented in table 1 .

Twenty three RA patients were currently not having treatment for RA, and their disease was considered to be inactive. Fifty six women were currently taking or had previously taken corticosteroids [mean (SD) dose $5.8(2.5) \mathrm{mg}$ prednisolon/d, range $2 \cdot 5-15.0 \mathrm{mg} / \mathrm{d}]$. The duration of corticosteroid treatment was $7 \cdot 7$ (7.2) years (range 1-31 years), and the mean cumulative prednisolone dose was $16.4 \mathrm{~g}$ (range $1 \cdot 1-131 \cdot 4 \mathrm{~g}$ ). Sixty four patients had never had corticosteroid treatment. Nonsteroid anti-inflammatory drugs (NSAIDs) were used by many RA patients $(n=107)$. Various non-steroid second line drugs (gold salts, salazopyridine, chloroquine, penicillamine) were used by 72 women.

Present or previous oestrogen replacement therapy was reported by 47 women with RA. The mean (SD) duration of such therapy was $3.8(3.0)$ years. Bilateral ovariectomy had been performed on 11 women. Only 60 patients reported having no disease other than RA (table 2).

\section{CONTROLS}

The control group comprised a selection of women with no history of a disease or medication known to affect bone metabolism. The exclusion criteria were: renal disease, liver disease, insulin-dependent diabetes, malignancy, rheumatoid arthritis, endocrine abnormalities in parathyroid or thyroid glands or in adrenals, malabsorption, previous partial or total gastrectomy, ovariectomy, premenopausal amennorrhea, alcoholism, long-term immobilisation, corticosteroid therapy, diuretics, cytotoxic drugs, anticonvulsive drugs, anabolic steroids, calcitonin, bisphosphonates and vitamin $\mathrm{D}$ therapy. Women who had used perimenopausal female hormones for over 12 months were excluded, although contraceptive hormone use was allowed. The control group consisted of 1611 women, of whom 1131 were postmenopausal. The mean (SD) age was 53.2 $(2 \cdot 8)$ years (table 1$)$.

\section{BONE DENSITY MEASUREMENT}

Bone mineral density was determined using dual-energy $x$-ray absorptiometry (DXA) (Lunar DPX, Madison, Wisconsin) at the spine (L2-L4) and left femoral neck. Quality standards were tested daily. The reproducibility of this method has proved to be good $-0.9 \%$ for the spine and $1.5 \%$ for the femoral neck measurements. ${ }^{9}$ There was evidence of marked lumbar osteophytes or spinal deformations in the DXA images of 15 women with RA, and these measurements were excluded. Similarly, 2 women with a deformity of the measured hip joint were 
Table 1 Characteristics, mean (SD) of patients with $R A(n=143)$ and controls $(n=1611)$

\begin{tabular}{|c|c|c|}
\hline & $R A$ & Controls \\
\hline Age (years) & $53 \cdot 7(2 \cdot 9)^{\star}$ & $53 \cdot 2(2 \cdot 8)$ \\
\hline Years since menopause (years) & $4.7(3.7)(n=106) \ddagger$ & $3 \cdot 3(3 \cdot 1)(\mathrm{n}=1131)$ \\
\hline Age at menopause (years) & $49.7(2.9) \dagger$ & $50 \cdot 6(2 \cdot 8)$ \\
\hline Weight $(\mathrm{kg})$ & $66.9(11.3) \dagger$ & $69 \cdot 7(12 \cdot 2)$ \\
\hline Height $(\mathrm{cm})$ & $161 \cdot 1(5 \cdot 0)$ & $161 \cdot 1(5 \cdot 4)$ \\
\hline Parity (n) & $2.5(1.3)$ & $2.7(1.4)$ \\
\hline Grip strength $(\mathrm{kPa})$ & $38 \cdot 2(21 \cdot 4) \ddagger$ & $62.5(15 \cdot 9)$ \\
\hline Calcium intake $(\mathrm{mg} / \mathrm{d})$ & $748(383)$ & $795(380)$ \\
\hline Alcohol intake (g/week) & $57(160) \ddagger$ & $126(150)$ \\
\hline Coffee intake $(\mathrm{dl} / \mathrm{d})$ & $3 \cdot 8(2 \cdot 2) \ddagger$ & $4 \cdot 4(2 \cdot 1)$ \\
\hline Smoking years (years) & $13 \cdot 6(8 \cdot 8)(n=33)$ & $15 \cdot 8(9 \cdot 5)(n=295)$ \\
\hline \multicolumn{3}{|l|}{ Daily walking/running } \\
\hline kilometers $(\mathrm{km})$ & $2.7(1.8) \dagger$ & $3.4(2 \cdot 9)$ \\
\hline \multicolumn{3}{|l|}{ Physical activity level } \\
\hline Functional grade $(1 / 2 / 3 / 4)(\%)$ & $\begin{array}{l}51 / 34 / 15 \\
9 / 29 / 48 / 14\end{array}$ & - \\
\hline Disease duration (years) & $15 \cdot 2(9 \cdot 7)$ & - \\
\hline \multicolumn{3}{|l|}{ Corticosteroid treatment $(n=56)$} \\
\hline Duration (years) & $7 \cdot 7(7 \cdot 2)$ & - \\
\hline Dose $(\mathrm{mg} / \mathrm{d})$ & $5 \cdot 8(2 \cdot 5)$ & - \\
\hline Spinal BMD $(\mathrm{g} / \mathrm{cm} 2)$ & $1.067(0 \cdot 161)(n=128) \ddagger$ & $1.129(0.157)(n=1465)$ \\
\hline Adjusted $^{a}$ & $1.092 \dagger$ & $1 \cdot 128$ \\
\hline Femoral BMD (g/cm2) & $0.851(0.136)(n=141) \ddagger$ & $0.932(0.123)(n=1611)$ \\
\hline Adjusted $^{\mathrm{a}}$ & $0.870 \ddagger$ & 0.930 \\
\hline
\end{tabular}

ameans adjusted for age, time since menopause and weight.

* significantly different from controls $(p<0.05)$.

tsignificantly different from controls $(p<0.01)$.

fsignificantly different from controls $(\mathrm{p}<0.001)$.

Table 2 Prevalence (past and current) of certain health disorders among patients with $R A(n=143)$

\begin{tabular}{|c|c|c|}
\hline Health disorder & $N$ & (\%) \\
\hline No disease other than RA & 60 & $42 \cdot 0$ \\
\hline Hypertension & 26 & $18 \cdot 2$ \\
\hline Hypercholesterolaemia & 21 & $14 \cdot 7$ \\
\hline Venous thrombosis in leg & 15 & $10 \cdot 5$ \\
\hline Cardiac insufficiency/arrhythmias & 14 & $9 \cdot 8$ \\
\hline Lactose malabsorption & 14 & $9 \cdot 8$ \\
\hline Hyperthyroidism $^{\mathrm{a}}$ & 12 & $8 \cdot 4$ \\
\hline Bilateral ovariectomy & 11 & $7 \cdot 7$ \\
\hline Coronary heart disease & 10 & $7 \cdot 0$ \\
\hline Pulmonary asthma/chronic bronchitis & 10 & $7 \cdot 0$ \\
\hline Hypothyroidism $^{\mathrm{b}}$ & 8 & $5 \cdot 6$ \\
\hline Cancer (non specified) & 3 & $2 \cdot 1$ \\
\hline Diabetes mellitus ${ }^{\mathrm{c}}$ & 2 & $1 \cdot 4$ \\
\hline Cerebrovascular accident & 1 & 0.7 \\
\hline Epilepsy & 1 & $0 \cdot 7$ \\
\hline Peptic ulcer & 1 & $0 \cdot 7$ \\
\hline
\end{tabular}

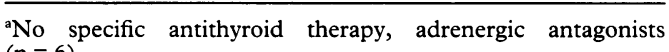
$(n=6)$

All with thyroxin therapy.

'Insulin dependent $(\mathrm{n}=1)$

excluded. In controls, 146 spinal and 12 femoral measurements were excluded. One hundred and twenty eight spinal and 141 femoral measurements from patients with RA, and 1465 spinal and 1599 femoral measurements from controls were available for analyses.

STATISTICAL ANALYSIS

The statistical analyses were carried out using the SPSS/PC-program. The data are expressed as means with SDs. BMD values of patients with RA are also expressed as percentages or as mean Z-scores of the control population. Comparability of the three RA groups was tested by the chi-square test. Single and multiple stepwise regression analyses were used to assess determinants of BMD and to derive equations to predict axial bone mass. A two-tailed unpaired Student's $t$ test and MannWhittney $U$ test were used to test differences between RA patients and controls. Analysis of variance and the Kruskall Wallis test were used to test differences between multiple groups.
The differences were located by the NewmanKeuls test. Analysis of covariance was used when adjustment for confounding factors was needed.

\section{Results}

Preliminary examination of the data showed no statistically significant differences in menopausal status, hormone use or morbidity between the three different RA groups (I inactive RA, II RA without corticosteroids, III RA with corticosteroids) so the data could be pooled for analysis. Patients with RA were significantly lighter and experienced menopause earlier than the control population. We also found differences in the consumption of coffee and alcohol. The physical activity of patients with RA was significantly lower than that of the controls. When all patients with RA were considered as one group $(n=143)$, the mean BMD both in the spine and femoral neck was significantly lower than those in the controls (Z-scores -0.39 for the spine and -0.66 for the femoral neck, respectively). The differences remained unchanged when the adjustments for age, weight and menopausal years were performed (table 1). Moreover, statistically significant differences existed between the patients with no other disease than RA and controls, both in the spine $(p=0.011)$ and femoral neck $(p<0.001)$. Spinal and femoral neck BMD did not differ between the patients with no disease other than RA $(n=60)$ and patients with RA with concomitant diseases $(\mathrm{n}=73)$.

Figures 1 and 2 show the mean BMDs in the three groups of patients with RA and controls. In the spine, there was a statistically significant difference only in corticosteroid treated RA patients (analysis of variance). In the femoral neck, a highly significant difference was also found between non-steroid treated RA patients and the controls.

The functional grade, physical activity and grip strength were lower in corticosteroid treated patients with RA than in patients with RA not taking corticosteroids. Ten patients in the corticosteroid group and 4 patients in the non-corticosteroid group had total prostheses. The mean BMD in the spine was significantly lower in the corticosteroid group. However, when the means were adjusted for age, time since menopause, weight and functional grade, the statistical difference disappeared. In the femoral neck, no significant differences between the groups were found (table 3 ).

Age and time since menopause correlated negatively with spinal BMD, but not with femoral BMD. Postmenopausal women with RA had significantly lower spinal BMD than premenopausal women $[1 \cdot 050(0 \cdot 159) v 1 \cdot 114$ $\left.(0.159) \mathrm{g} / \mathrm{cm}^{2}, \mathrm{p}=0.04\right]$, whereas at the femoral neck the difference was not statistically significant $[0.842(0.132) \quad v 0.876(0.145)$ $\mathrm{g} / \mathrm{cm}^{2}, \mathrm{p}=0 \cdot 190, \mathrm{NS}$ ]. Weight was highly correlated with BMD at both measured sites. A positive relationship was also found between BMD and grip strength. In patients treated with corticosteroids, a negative correlation was 


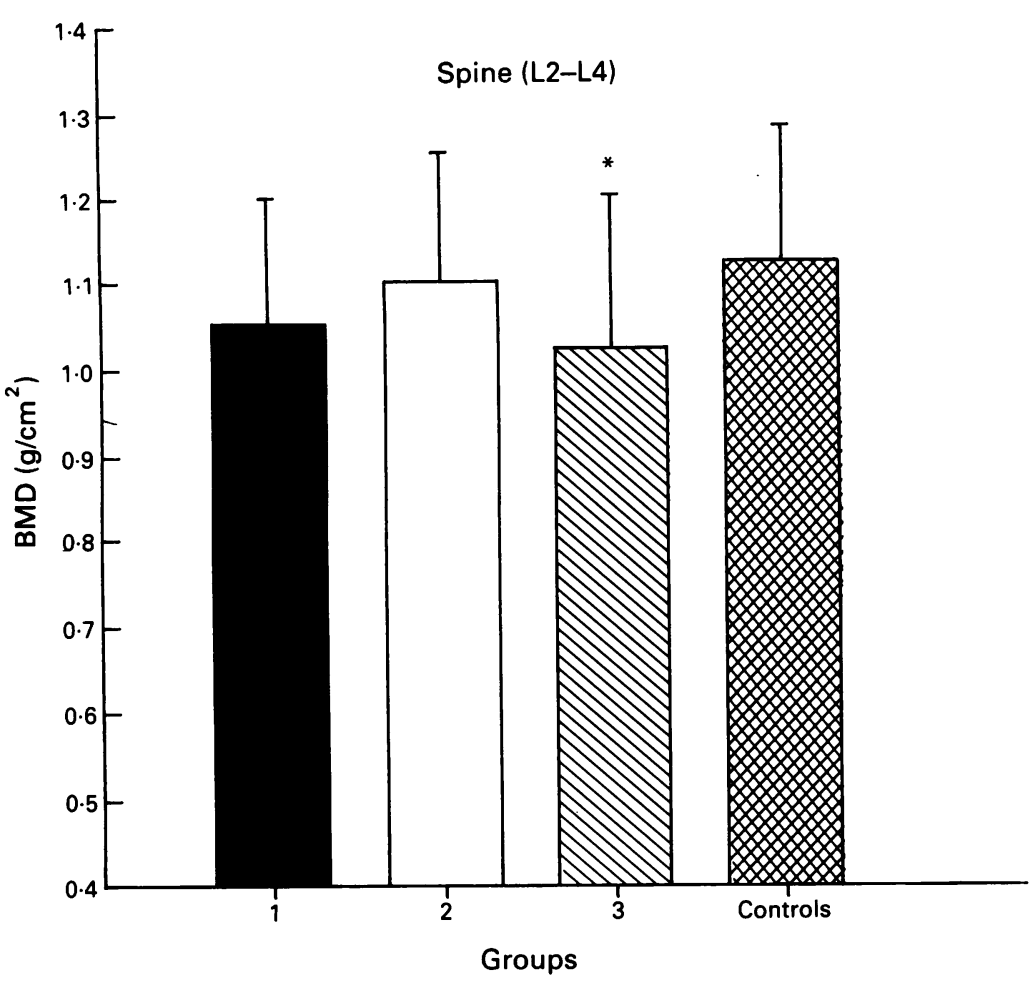

Figure 1 Bone mineral density (BMD) of the spine in the controls $(n=1465)$ and in three groups of patients with $R A$. ( 1 , patients with no drug therapy $(n=22) ; 2$, patients with no corticosteroid treatment $(n=56) ; 3$, patients with past or current corticosteroid treatment $(n=50))$.

$Z$-scores for the $R A$ groups are $-0 \cdot 47,-0 \cdot 16$, and $-0 \cdot 64$, respectively.

* significant difference $(p<0.05)$ compared with controls.

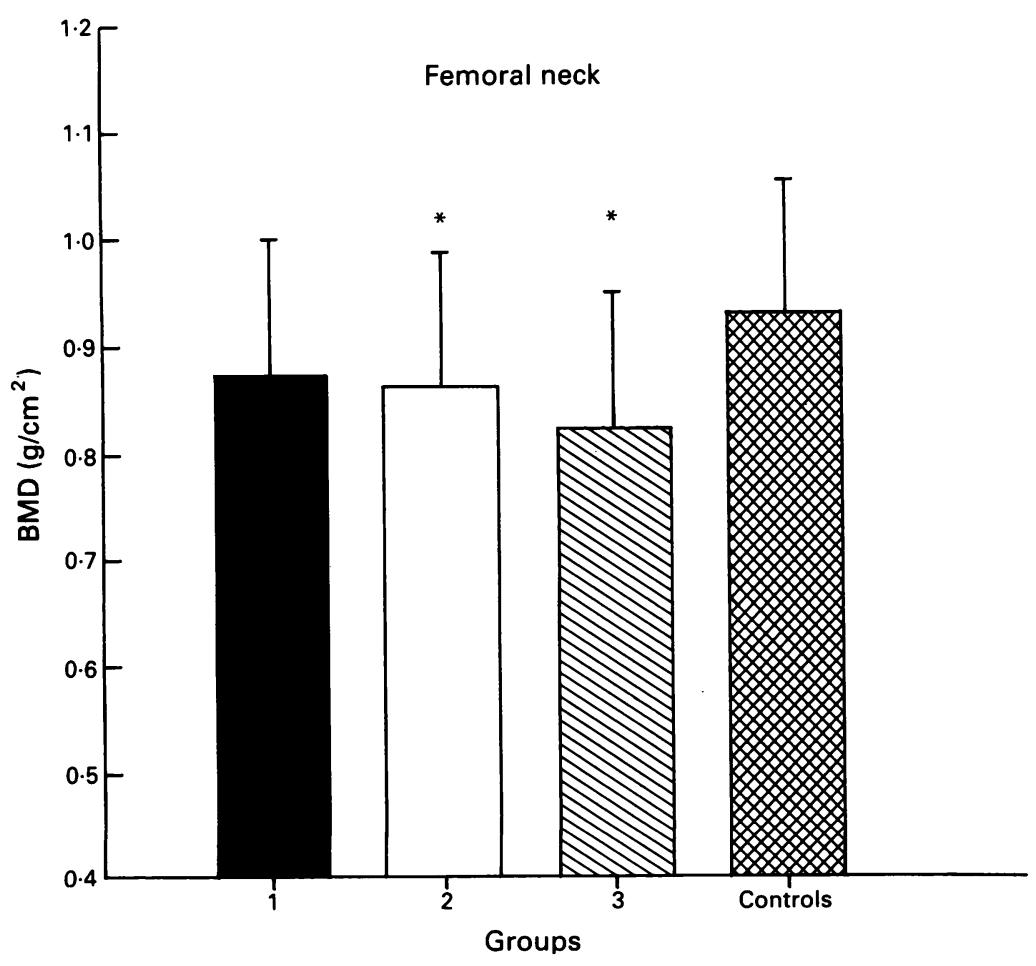

Figure 2 Bone mineral density (BMD) of the femoral neck in the controls $(n=1599)$ and in three groups of patients with $R A$. (1, patients with no drug therapy $(n=23) ; 2$, patients with no corticosteroid treatment $(n=64) ; 3$, patients with past or current corticosteroid treatment $(n=54))$.

$Z$-scores for the $R A$ groups are $-0 \cdot 46,-0 \cdot 54$, and -0.87 , respectively.

* significant difference $(p<0.001)$ compared with controls. found between femoral BMD and the duration of corticosteroid treatment. Similarly, disease duration correlated negatively with femoral BMD (table 4). We could not find any significant correlation between $\mathrm{BMD}$ and calcium intake, smoking habits, alcohol consumption, coffee consumption or hormone use. There was no significant difference between patients with RA taking and those not taking oestrogens (data not shown).

Multiple regression analysis found age, weight and functional grade to be significant predictors of spinal BMD $\left(\mathrm{R}^{2}=0.403\right.$, $\mathrm{p}<0.001)$. In the femoral neck, weight, cumulative corticosteroid dose and functional grade were significant predictors of $\mathrm{BMD}$ $\left(R^{2}=0.410, \quad p<0.001\right) \quad$ The regression equations were:

Spinal $\quad \mathrm{BMD}=1.424+0.007$ * Weight $(\mathrm{kg})-$ 0.018 * Age $(\mathrm{y})+0 \cdot 049$ * Functional grade

Femoral Neck BMD $=0.317+0.007$ * Weight (kg) -0.0018 * Cumulative corticosteroid dose (g) $+0.027^{\star}$ Functional grade

\section{Discussion}

The present population-based study found lower axial BMD in a group of perimenopausal women with RA. Further analysis demonstrated that the femoral neck BMD was lower in patients with active disease requiring drug therapy. At the spine, the difference was most pronounced in corticosteroid treated patients. Our results agree with previous studies that have demonstrated lower axial BMD in patients with RA. ${ }^{371011}$ Contrary conclusions have been reached by others, however. ${ }^{2} 12$ Differences in study designs and methods for BMD measurements might partly explain the different results.

There is considerable disagreement whether axial osteoporosis is related to non-steroid treated RA. ${ }^{41314}$ The present study showed that RA patients who had never been treated with oral corticosteroid also have lower axial BMD than the control population, especially in the proximal femur. RA patients with inactive disease did not differ significantly from the normal population. The results agree with Sambrook et al, ${ }^{13}$ who found lower spinal and femoral neck BMD in 40 women with RA who had not received corticosteroids. Similar results were obtained by Magaro et al. ${ }^{14}$ In contrast, Laan et $a l^{7}$ were unable to demonstrate a significant BMD decrease in patients with RA without corticosteroid treatment compared with normal reference data. Their study, however, used quantitative computed tomography, and reference values from previous reports were used instead of a real control group.

The role of corticosteroid in causing bone loss in RA is controversial..$^{5-7} 15$ In the present study the decrease in BMD at the lumbar spine was most marked in patients with corticosteroid treatment. However, patients treated with corticosteroids had slightly longer duration of RA and significantly greater functional impairment as assessed with 
Table 3 Comparison between patients with $R A$ treated with second line drugs and/or NSAIDs $(n=64)$ and patients with $R A$ with current or past corticosteroid treatment $(n=56)$

\begin{tabular}{lcc}
\hline & $\begin{array}{l}\text { RA with no } \\
\text { corticosteroids }\end{array}$ & $\begin{array}{l}\text { RA with } \\
\text { corticosteroids }\end{array}$ \\
\hline Age (years) & $53 \cdot 8(2 \cdot 9)$ & $53 \cdot 3(3 \cdot 0)$ \\
Menopausal age (years) & $5 \cdot \cdot 1(2 \cdot 5)(\mathrm{n}=53)$ & $49 \cdot 5(3 \cdot 3)(\mathrm{n}=39)$ \\
Years since menopause (years) & $4 \cdot 2(3 \cdot 3)$ & $4 \cdot 5(3 \cdot 6)$ \\
Weight (kg) & $68 \cdot 6(10 \cdot 3) \dagger$ & $65 \cdot 9(12 \cdot 5)$ \\
Height (cm) & $161.5(5 \cdot 0)$ & $160 \cdot 5(4 \cdot 9)$ \\
BMI (kg/m2) & $25 \cdot 9(3 \cdot 7)$ & $25 \cdot 2(4 \cdot 4)$ \\
Disease duration (years) & $13 \cdot 9(10 \cdot 8)$ & $15 \cdot 0(8 \cdot 2)$ \\
Grip strength (kPa) & $43 \cdot 6(18 \cdot 7)$ & $28 \cdot 5(19 \cdot 4) \ddagger$ \\
Daily walking/running (km) & $2 \cdot 9(1 \cdot 8)$ & $2 \cdot 2(1 \cdot 4) \dagger$ \\
Functional grade $(1 / 2 / 3 / 4)(\%)$ & $3 / 27 / 51 / 19$ & $18 / 40 / 33 / 9 \dagger$ \\
Lumbar BMD (g/cm2) & $1 \cdot 106(0 \cdot 146)(\mathrm{n}=56)$ & $1 \cdot 029(0 \cdot 176)$ \\
& & $(\mathrm{n}=50)^{\star}$ \\
Adjusted BMD & $1 \cdot 048$ & $0 \cdot 825(0 \cdot 152)(\mathrm{n}=54)$ \\
Femoral BMD (g/cm2) & $0 \cdot 865(0 \cdot 123)(\mathrm{n}=64)$ & $0 \cdot 838$ \\
Adjusted BMD & $0 \cdot 858$ & \\
\hline
\end{tabular}

${ }^{\mathrm{a}} \mathrm{BMD}$ values adjusted for age, time since menopause, weight, disease duration and functional group.

${ }^{\star} \mathrm{p}<0.05$ between the groups.

tp $<0.01$ between the groups.

$\neq \mathrm{p}<0.001$ between the groups. the mean dose of prednisone was slightly higher in their study. One cannot exclude the possibility that there are differences in the indications for corticosteroid treatment between the countries. Our results are in agreement with Sambrook et al, ${ }^{6}$ who used dualphoton absorptiometry (DPA) and found no difference in annual BMD changes between RA patients treated with low-dose corticosteroid and patients without such therapy. We suggest that low-dose corticosteroids are relatively harmless to bone mass when used in an active disease which threatens a patient's mobility. Although corticosteroid treatment is associated with an increased risk of low BMD, the independent contribution of corticosteroids may be minimal.

Body weight was found to be an important determinant of BMD both at the spine and femoral neck. This relationship has also been shown in normal subjects by several investigators, ${ }^{9} 1617$ but this relationship may be partly due to the DXA technique, which expresses BMD as area density. ${ }^{18}{ }^{19}$ However, body weight may be related to total body fat, which has been shown to be an important determinant of BMD in postmenopausal women. ${ }^{20}$ Increased mechanical load on bones in obese persons and peripheral production of oestrone in fat tissue have been proposed as explanations. RA patients were lighter than controls, and this may indicate that fat mass, lean body mass or both are lower in these patients. Although, fat mass and lean body mass were not measured in our patients, we suggest that lower weight is also related to RA.

Reduced mobility has been suggested as a cause of generalised osteoporosis in RA. Significant relationships were found between forearm BMD and functional impairment and duration of the disease by Als et al. ${ }^{21}$ Sambrook et $a l^{3}$ using multiple regression analysis found that physical activity was a significant predictor of femoral BMD in female RA patients. In a recent prospective study by Laan et $a l^{22}$ duration of RA, disease activity and functional impairment were negatively associated with $\mathrm{BMD}$ at the proximal femur. Our results show that the degree of functional impairment is associated with both decreased spinal and femoral neck BMD in patients with RA. Similar results were obtained using crude correlations and multivariate analysis. Impaired physical activity may be due to increased levels of disease activity. Unfortunately, owing to the population-based design of the present study we have no data on erythrocyte sedimentation rate or number of inflamed joints. Consequently, we can not draw definite conclusions about the influence of disease activity on BMD findings. However, patients with inactive RA did not differ significantly from the control population. Our results and recently published findings suggest that the most important contributing factor for generalised osteoporosis in RA is the physical impairment of the patients.

We found a negative correlation between disease duration and BMD at the femoral neck, suggesting that disease related mechanisms are the DXA method measures integral bone mass of the vertebrae, whereas pure trabecular bone could be measured with QCT. Furthermore, 
responsible for the lower $\mathrm{BMD}$ in patients with RA. However, in multivariate analysis the disease duration was not a significant predictor of BMD. In common with the present study, most previous studies have not been able to show a correlation between disease duration and BMD. ${ }^{10} 1121$ Hence, physical impairment seems to be a more significant determinant of axial BMD than the duration of RA.

Smoking, alcohol and low calcium intake have been suggested as risk factors for osteoporosis. ${ }^{16}{ }^{23}$ However, we were unable to find any significant effect of alcohol intake, smoking history or daily calcium intake on axial BMD in patients with RA. It may be that the major contribution of disease-related factors masks the effects of lifestyle risk factors on BMD. Parity has been suggested to have a favourable effect on BMD in RA patients. ${ }^{3}$ Although there was a significant correlation between parity and femoral BMD in our study, this was not confirmed in multivariate analysis. The assumed positive effect of oestrogens on BMD were not found in this study. However, several confounding factors may influence the results. Furthermore, the number of patients using oestrogen for a longer time was too small to allow reliable conclusions on this topic.

Cross-sectional studies such as this study present certain methodological problems. Firstly, the severity of the disease and functional disability may vary during the course of the disease. In fact, these factors are usually associated with each other. Secondly, corticosteroid treatment is usually started in patients with more active disease and decreased mobility, so it is difficult to distinguish the effects of treatment and those of disease on bone mass. The follow up of the present study population is expected to provide more exact information about the determinants of BMD in RA.

A major advantage of this investigation is the population-based design of the study. Although most of the patients had concomitant diseases, they represent all patients with $R A$ in a defined population. The analysis of medical records in a sample of women confirmed the validity of our RA diagnosis. Most previous studies have included only patients with RA with no other diseases or drug therapy known to affect bone metabolism. ${ }^{7} 1011$ However, there has been one population-based study on fractures in $\mathrm{RA},{ }^{24}$ which found a small increase in the incidence of osteoporotic fractures in RA patients.

In conclusion, this population-based study shows that women with RA have lower axial BMD: $5 \cdot 5 \%$ lower at the spine (Z-score - $0 \cdot 39)$ and $8.7 \%$ lower a the femoral neck (Z-score $-0 \cdot 66)$ compared with normal population. The additional negative effect of low-dose corticosteroid treatment on BMD was minimal in this study. As the most significant diseaserelated determinant of BMD both in the spine and femoral neck is decreased functional ability, every effort should be used to keep patients with RA mobile. On the basis of recent findings about the relationship between low bone mass and fractures, ${ }^{25}$ we suggest that women with active RA are at an increased risk of future fractures.

This study was supported in part by a grant from the Academy of Finland.

1 Sambrook P N, Ansell B M, Foster S, Gumpel J M, Hesp $R$, Reeve J. Bone turnover in early rheumatoid arthritis. II. Longitudinal bone density studies. Ann Rheum Dis 1985; 44: $580-4$.

2 Verstraeten A, Dequeker J. Vertebral and peripheral bone mineral content and fracture incidence in postmenopausal patients with rheumatoid arthritis: effect of low dose corticosteroids. Ann Rheum Dis 1986; 45: 852-7.

3 Sambrook P N, Eisman J A, Champion D, Yeates M G, Pocock N A, Eberl S. Determinants of axila bone loss in Pocock N A, Eberl S. Determinants of axila bone loss in

4 Laan R F J M, van Riel P L C, van Putte L B A. Bone mass in patients with rheumatoid arthritis. Ann Rheum Dis 1992; 51: 826-32.

5 Als O S, Gotfredsen A, Christiansen C. The effect of glucocorticoids on bone mass in rheumatoid arthritis patients. Arthritis Rheum 1985; 28: 369-75.

6 Sambrook P N, Cohen M L, Eisman J A, Pocock N A, Champion $G D$, Yeates $M$ G. Effects of low dose corticosteroids on bone mass in rheumatoid arthritis: a longitudinal study. Ann Rheum Dis 1989; 48: 535-8.

7 Laan R F J M, van Riel P L C M, van Erning L J T O, Lemmens J A M, Ruiks S H J, van de Putte L B A. Vertebral osteoporosis in rheumatoid arthritis patients: Vertebral osteoporosis in rheumatoid arthritis patients:
effect of low dose prednisone therapy. $B r \mathcal{F}$ Rheumatol effect of low dose

8 Tuppurainen $M$, Honkanen $R$, Kröger H, Saarikoski S, Alhava E. Osteoporosis risk factors, gynaecological history and fractures in perimenopausal women-the results of the baseline postal enquiry of the Kuopio Osteoporosis Risk Factor and Prevention Study. Maturitas 1993; 17: 89-100.

9 Kröger H, Laitinen $\mathrm{K}$. Bone mineral density measured by dual-energy $\mathrm{x}$-ray absorptiometry in normal men. Eur $\mathcal{f}$ Clin Invest 1992; 22: 454-60.

10 Compston J E, Crawley E O, Evans C, O'Sullivan M M. Spinal trabecular bone mineral content in patients with non-steroid treated rheumatoid arthritis. Ann Rheum Dis non-steroid treated

11 O'Malley M, Kenrick A J, Sartoris D J, et al. Axial bone density in rheumatoid arthritis: comparison of dualenergy projection radiography and dual-photon absorptiometry. Radiology 1989; 170: 501-5.

12 Eggelmeijer F, Camps J A J, Valkema R, et al. Lumbar bone mineral density in rheumatoid arthritis, normal values in ambulant, non-steroid treated patients. $\operatorname{Br} \mathcal{F}$ Rheumatol 1991; 30 (suppl 2): 53 .

13 Sambrook P N, Eisman J A, Champion G D, Pocock N A, Yeates $M$ G, Eberl $S$. Osteoporosis in rheumatoid arthritis: safety of low dose corticosteroids. Ann Rheum Dis 1986; 45: 950-3.

14 Magaro M, Piane T D, Zoli A, Serra F, Altomomte L, Mirone L. Generalized osteoporosis in non-steroid Mirone L. Generalized osteoporosis in non-steroid treated
73.76.

15 Reid D M, Kennedy N S J, Smith M A, et al. Bone loss in rheumatoid arthritis and generalised osteoarthritis: effects of corticosteroids, suppressive antirheumatic drugs and calcium supplements. Br $\mathcal{F}$ Rheumatol 1986; 25: 253-9.

16 Stevenson J S, Lees B, Devenport M, Cust M P, Gange K F. Determinants of bone density in normal women: risk factors for future osteoporosis. $B M \mathcal{F} 1989 ; 298:$ 924-8.

17 Geusens P, Dequeker J, Verstraeten A, Nijs J. Age-, sex- and menopause related changes of vertebral and peripheral bone: population study using dual and single photon bone: population study using dual and single photon
absorptiometry and radiogrammetry. $\mathscr{f}$ Nucl Med 1986; 27: 1540-9.

18 Kröger H, Kotaniemi A, Vainio P, Alhava E. Bone densitometry of the spine and femur in children by dualenergy x-ray absorptiometry. Bone and Mineral 1992; 17 75-85.

19 Carter D R, Bouxsein M L, Marcus R. New approaches for interpreting projected bone densitometry data. $\mathcal{F}$ Bone Miner Res 1992; 7: 137-145.

20 Reid I R, Ames R, Evans M C, et al. Determinants of total body and regional bone mineral density in normal postmenopausal women-a key role for fat mass. 7 Clin Endocrinol Metab 1992; 75: 45-51.

21 Als O S, Gotfredsen A, Riis B J, Christiansen C. Are disease duration and degree of functional impairment determinants of bone loss in rheumatoid arthritis? Ann determinants of bone loss in
Rheum Dis 1985; 44: 406-11.

22 Laan R F J M, Buijs W C A M, Verbeek A L M, et al. Bone mineral density in patients with recent onset rheumatoid mineral density in patients with recent onset rheumatoid
arthritis: influence of disease activity and functional arthritis: influence of disease activity and

23 Cumming $R$ C. Calcium intake and bone mass: a quantitative review of the evidence. Calcif Tissue Int 1990 47: 194-201.

24 Hooyman J R, Melton L J III, Nelson A M, O'Fallon W $M$, Riggs B L. Fractures after rheumatoid arthritis. Arthritis Rheum 1984; 27: 1353-61.

25 Cummings S R, Black D M, Newitt M C, et al. Bone density at various skeletal sites for prediction of hip fractures. Lancet 1993; 341: 72-75. 